\title{
THE APPLICATION OF CHOICE-BASED CONJOINT MODEL TO STUDY GOVERNMENT AUTHORITIES PREFERENCE ACase of Traffic-Subsidy-Pollution Related Policy in Indonesia
}

\author{
Gudono \\ Faculty of Business and Economics, Universitas Gadjah Mada University
}

According to the UN, air pollution kills more than 3 million people each year (UN-Habitat 2007). Despite the magnitude of the impact, delays in making decisions about the environment are quite common among governments worldwide. The purposes of this study are twofold. First, the study is to investigate the relative strength of attributes of environmental policy such as methods of vehicle restriction, percentage of reduction in lead (and CO2) content, and percentage of subsidy reduction. Second, the study is to test government choice when it faces conservative, "scientific," and popular policy alternatives. To achieve both objectives this research uses an experimental method. The orthogonal design is adopted for stimuli presentation and conjoint analysis is used for data analysis. The research participants are students of an accounting graduate program of a state university in Java (Indonesia).

The results suggest CO2/lead reduction has the strongest effect on policy maker preference. In addition, those policy makers tend to prefer the status quo condition which indicates conservative views. This is demonstrated by the tendency of their choice on an alternative policy package which requires mini- 
mum changes compared with the existing policies (a maximum utility of 64.3 percent vs. 28.6 percent and 7.1 percent of other alternatives). In addition, bureaucrats tend to play "safe" (namely the reduction of lead content in gasoline) when the possibility of resistance is imminence. Some consequences of the research findings are also discussed.

Keywords: conjoint analysis; mixed environmental; public policy; utility function

\section{Background}

The Government of Indonesia, especially under the regime of Susilo Bambang Yudhoyono (SBY), has been frequently criticized for being slow in making strategic decisions, including decisions about issues that can have serious repercussions on the environment (WaspadaOnline 2010; PMEIndonesia.Com 2008). This can be seen from the SBY government's inaction on reducing fuel subsidies (an issue that has remained pending for more than 2 years) and the restriction of motorized vehicles on the highway. The impact of inaction is devastating. For example, fuel subsidy increases year by year (AntaraNews.Com 2008). In addition, traffic congestion in big cities is getting worse (RakyatMerdekaOnline 2010).

Slowness in making decisions related to saving the environment also seems prevalent in many countries (UNFCCC 2010). The fact that the Kyoto Protocol can only be accepted fully 20 years after its declaration is real evidence that many governments use a slow adoption strategy when they evaluate more stringent standards re- garding air pollution. Implications of the problem can be seen from the following data: according to the UN, air pollutionkills more than 3 million people each year (UN-Habitat 2007), 925 million people are experiencing a hunger (FAO 2010), and 1.4 billion people in 2005 earned less than $\$ 1.25$ per day (World Bank Development Indicators 2008). UN data showed that $\mathrm{CO} 2$ emissions would increase 60 percent between 1997 and 2010 and 60 percent of the increase would be contributed by developing countries.

Slowness in taking major steps associated with environmental issues may be caused by the complexity of factors that decision makers, i.e., government officials, must consider, especially with regard to economic and political issues. In such situations, the diverse factors may result in anxiety, inability to achieve the best solutions, and/or slow response. Prior studies relate those phenomena to cognitive dissonance (Aronson et al. 2006) and bonded rationality (Rubinstein 1998). In many developing countries, the importance of economic factors is obvious because the economic structure of many developing countries is simply 
Gudono-The Application ofChoice-BasedConjointModeltoStudyGovernmentAuthoritiesPreference

extractive by nature: sucking resources from Mother Nature and exhausting them. Examples may include coal mining for energy creation in Northeast Asia countries (e.g., China, South Korea, North Korea, and Mongolia) and deforestation which today is still happening in Indonesia and Brazil. If the extractive activity is reduced, those governments are worried they will lose their source of income from the tax on those activities and that consequently it would reduce their ability to grow the economy. Another economic reason might relate to the shift in national economic ideology which has become pro-market. For example, the change in China from a socialist system to a pro-market system has led to the emergence of consumerist life styles. While the move increases economic growth, simultaneously the move also boosts the exploitation of natural resources.

Indonesia is not an exception. After the fall of Suharto in 1998, many fundamental changes occurred in Indonesia's economic and political system. The implementation of Law No. 32/2004 on regional autonomy and Law No. $25 / 1999$ on fiscal balance motivates local governments to become more responsive to what is needed by their people. Despite major change in many areas, Indonesia's environmental condition remains constant, if not getting worse, due to lack of comprehensive regulations that protect the environment from excessive exploitation. Law No. 32 has resulted in pressure to raise "local original revenues" (PAD) which consequently forces lo- cal authorities (i.e., regents, mayors, and governors) to adopt more innovative maneuvers in exploiting areas under their control at all costs.

This explains why, when local governments face the two alternatives of either raising revenues to fund their expenditure or preserving the environment for future generations, the choice seems to them to be obvious: they are more likely to deplete the natural resources. The fact that the central government and many local authorities are not politically strong makes the situation even worse, since they are also afraid of facing a hostile response from people when making policy that is not popular. The fact that in the era after the Suharto regime there has been no single ruler whose mandate was backed by a majority vote-SBY's party itself is supported only by 35 percent of votes - might explain delays and weak adoption of strong environmental policies.

A major issue related to policymaking that has an impact on the environment is this: although the government and the public are aware of the long-term negative effects of the situation, government officials are usually slow to respond to the problems; when it finally does respond, the solutions are only piecemeal. In Indonesia, at the end of 2009, the people were still waiting for the government to deliver its promise to create more realistic regulations related to gasoline and many related non-government organizations are warning the government continually about the deteriorating environmental conditions. Unfortunately, de- 
spite the serious effects of the government inaction, until now there has not been much research focused on the topic.

Consequently, how people consider mixed environmental factors and make up their minds, remain a mystery. The main objective of this study is to investigate the preferences of public officials in making choices related to air pollution reduction policies. In particular, this study analyzes the utility function of government officials when they evaluate features of environmentrelated policies. Another aim is to introduce the use of a choice-based model using conjoint analysis in environmental policy analysis (Elrod et al. 1992). This is an exploratory study since very little is known regarding the utility function of government officials in the area of environmental policy analysis. Despite the exploratory nature of this study, the issue being studied and the approach being used in this research could later be adopted to extend to issues and methodologies in the areas of governmental strategic management, psychology of economics, as well as governmental management accounting.

\section{Literature Review}

\section{Population, Economic, and Environmental Degradation}

Economic growth is essential to support rising consumption and to provide the jobs necessitated by population increase. It seems obvious that population is a direct threat to the environment. In accordance with the concept of "ecological footprint" (Wachernagel and Rees 1995), green plants are an essential requirement to clean up carbon dioxide (and the "greenhouse effect", etc.) resulting from economic development to support the consumption of the population (such as burning coal for electrical energy). But to clear the negative impact of one person's consumption, acres of plantation are needed. Note the following measure of ecological footprint: for one person in North America needed 20-25 acres of crops to provide food and assimilate waste. Wachernagel and Rees (1995) argue that the world ecological footprint already exceeds the world's supply of productive land.

The above problems become more complex when social variables such as health, social justice and politics are taken into account in the study of the devastating impact of population growth. Research shows that poor sanitation - as a result of population growth again as well as the pollutionis directly related to the level of child mortality: in Africa every year five million children die (Unicef 2008). In Brazil the estimated proportions of respiratory deaths attributed to $\mathrm{CO}, \mathrm{SO} 2$, and PM10, Pls - considered individually - arearound 15,13, and 7 percent, respectively (Conceicao et al. 2001). Linking environment and justice problems, we witness cases where people in water rich areas in Latin America are short of water (Beeson 2008). It seems the problem is also caused by 
Gudono-The Application ofChoice-BasedConjointModeltoStudyGovernmentAuthoritiesPreference

political problems surrounding water, where several governments in Latin America (e.g., Uruguay) are forced to negotiate with the IMF about conducting privatization of water systems.

Events that are not so much different in fact can also be found in Indonesia. For example, water pollution in major cities in Indonesia has caused high rates of infant mortality (World Bank 2008). Furthermore, the entry of foreign investors into the business of providing drinking water has happened in Jakarta and Surabaya. Not so long ago, a market leading, state-owned water company was acquired by a multinational company (as in the case of PT Golden Mississippi purchased by DANONE). ADB data in 2008 states that water pollution in Indonesia is causing a loss of Rp48 trillion per year. It appears that the link between "population" affects $\rightarrow$ "economic development" affects $\rightarrow$ "environmental problems" affects $\rightarrow$ "social problems" also threatens Indonesia.

In addition to water, air is also adversely affected by the growing size of the Indonesian population. With increasing population, the number of vehicles has also increased, so worsening air quality. Besides this, budget pressures are also increasing because the infrastructure (roads and bridges) that the government should provide is increasing. On the other hand, governments also face pressure to provide large quantities of gasoline and this depletes oil fields of Indonesia. The data show that from the year 2001 to
2008 , the number of vehicles increased from 3,5 million to 9,6 million (Vivanews.Com 2010). For all of Indonesia in the year 2008 there are more than 70 million vehicles (Statistics Indonesia 2009). The number is growing at about 24 percent per year. With the increasing number of vehicles is not surprising that government subsidies for fuel are also getting bigger $(\mathrm{Rp} 80$ trillion and will soon increase to Rp120 trillion, after parliament approved the increase in subsidy).

\section{Complexity Surrounding Environmental-Related Decision Making}

The complexity of decision-making related to the environment is caused not only by difficulties in the assessment of environmental impacts but also by the many interested parties willing to intervene. A study showed that the pressure from ENGOs has an impact on air pollution levels (Binder and Neumayer 2005). Moreover, even ideology and culture also affect decisions related to the environment. As seen today: capitalist/consumerist ideology tends to encourage economic policies that could destroy Mother Nature in the name of satisfying consumer needs (Klein 2000). In public, political leaders -mostly government figures- may talk about nice concepts like sustainable development or green policy, however in many cases this is only lip service. In reality, the environment is the lowest priority. 
Gadjah MadaInternationalJournal of Business,September-December 2010, Vol.12,No.3

Many factors must be considered in making such decisions and this leads to difficulty in determining which option is the best. Public officials often have to determine priorities (tradeoffs) between economic reasons versus environmental reasons. For example, to decide which is the more important between an increase in fuel prices or a reduction on the number of vehicles? In addition a decision package can also contain a combination of features simultaneously, so the package of decisions that can be compared with another which is preferred in accordance with the composition of existing features. In the context of policy issues related to the impact of population on the number of vehicles, some aspects that are often considered include:

1. How to reduce the number of vehicles on the highway; such as whether to increase gasoline prices by making sales quotas or vehicle.

2. How big is the target of reducing the content of $\mathrm{CO} 2$ that need to be set?

3. By how much should subsidies be reduced?

Due to the nature of these features, which are not easily assessed objectively, the judgment of the decision maker plays a dominant role. It is not impossible that the actual suitability of a policy depends on the subjective decision-maker preference of features related to policy choices.

\section{Information Integration and Decision Maker Preference}

In the private sector, business failures, e.g. bankruptcies, are often studied using the agency theory framework because the failure is thought to be caused by moral hazard or adverse selection of the management (the agent, see Barney 2002). The framework is appropriate when the principal-agent relationship is well defined and information asymmetry does exist. However, in the context of public policy, such as those related to the implementation of sustainable development programs, principal-agent relationship is often vague. One might think that the people's representatives (members of The House) are the principals. In many (if not all) cases, it is not true because the departmental ministers and/or other government officials are subordinate to the president. Furthermore, in reality parliament cannot really control, or even effectively monitor, the government officials. In fact, news media shows that in many cases members of the parliament are successfully coopted by bureaucrats (executives who should be supervised). In this regard, understanding the psychology of public officials in choices related to development programs is important to investigate.

One theory that seems able to explain how pieces of information determine the judgments of a decision maker is the information integration 
Gudono-The Application ofChoice-Based ConjointModeltoStudyGovernment AuthoritiesPreference

theory (Anderson 1991). Information integration theory explores how attitudes are formed and changed through the integration (mixing, combining) of new information with existing cognitions or thoughts. According to information integration theory, every piece of information will have value and weight such that the attitude of someone which is formed, after considering all information, can be modeled as follows:

$$
y=\sum_{i=1}^{n} w_{i} \cdot v_{i}
$$

where

$\mathrm{y}=$ attitude,

$i=$ number of pieces of information,

$\mathrm{w}=$ weight, and

$\mathrm{v}=$ value of the information. Since the " $w$ " and " $v$ " could resemble information from different areas, the model is suitable for studying the effect of mixed factors on decision makers' attitudes.

This study uses part worth function (= utility function) as a representation of the information integration theory's model. Hence, the part worth function is basically a model of how government officials evaluate the attributes of the policy package and make their decisions. To conduct such analysis a technique known as conjoint analysis (conjoint is the acronym 'Considered jointly') is implemented. The technique is commonly used in marketing research area (e.g., Rosko et al. 1985; Schaupp and Belanger 2005). The conjoint analysis model is classified as a discrete-choice model where the preference or the choice made by respondents (= decision makers) is considered as an additive function of the contribution of all attribute levels in influencing the perceptions of decision makers. The model is as follows.

$$
U(X)=\sum_{m=1}^{M} \sum_{k=1}^{K} \alpha_{k m} \cdot x_{k m}+E
$$

where

$\mathrm{U}(\mathrm{X})=$ thepreferensi (utility),

$\mathrm{K}=$ the level of attributes,

$\mathrm{M}=$ the number of attributes,

$\alpha_{\mathrm{km}}=$ thecontribution of each attribute level,

$\chi_{\mathrm{km}}=0$, if an attribute is not relevant level (not considered) and

$\chi_{\mathrm{km}}=1$, if an attribute level considered.

Conjoint analysis (CA) has several advantages. First, the CA can be used to examine the impact of tradeoffs between attributes of objects (services) on the decision. Second, as has been done in marketing research, CA can be used to evaluate the product concept (the concept of policy) that does not exist (yet to be decided). In the context of studying sustainable development, $\mathrm{CA}$ is appropriate because many sustainable programs under evaluation have not been implemented, yet and furthermore, the strategic programs may contain conflicting features. Using data of each respondent's part worth function CA is expected to choose an object (concept) that con- 
Gadjah MadaInternationalJournal ofBusiness,September-December 2010,Vol.12,No.3

tains an optimal combination of features.

\section{Research Methods}

\section{Nature of Study and Sampling Method}

This study is an experiment using a sample of civil servants (PNS) who were pursuing their master degree in accountancy in a state university in Java (Indonesia). The sampling process is not random and the researcher established two criteria. First, the experiment participants should have been working as civil servants for a minimum of 5 years or should have served as a fourth echelon in his/her institution. Second, the subject should have taken a course in management accounting, strategic management, or management control system. Non random sampling is implemented to ensure efficient process of selecting research participants who satisfy both sample requirements. Five years of working experience was required to assure that participants are reasonable representation of true government officials. A sample of eight students participated in the experiment, but after reviewing their responses, one student was dropped from the sample due to the incompleteness of her response. Unlike the other parametric statistics, in CA small sample size $(8-1=7)$ would not be a barrier (Hair et al. 1995, see also Kotri 2006).

\section{Experimental Design, Instrumentation, and Validation}

Rather than using a full factorial design, to reduce the complexity of the experiment, the researcher used a fractional design, or more precisely, an orthogonal design to ensure the efficiency in research design. In addition, researchers used four holdouts and 3 groups of simulations.

For instrumentation the researcher used "full profile card-sort" approaches (Hair et al. 1995; Gudono, upcoming) in which respondents were asked to observe cards that contain descriptions about various attribute levels of pollution control related to a policy package and thereafter were to express the level of their preference by using the ordinal scale (ranking). Before the respondents answers were taken, researchers observed their answers at a glance to find errors in the answer sheets. If errors were found then the students were asked to correct them. Note that in CA, similar (double) answers in more than one card are not allowed. Likewise, the rankings over the maximum number of options must be dropped. To detect the validity of the answers, researchers used a cross validation by utilizing holdouts data.

\section{Scenarios and Stimuli}

The research participants asked to observe the stimuli associated with air pollution reduction policies, especially the emission of toxic gases car- 
Gudono-The Application ofChoice-BasedConjointModeltoStudyGovernmentAuthoritiesPreference

bon dioxide and lead in the air. Stimuli are experimental treatments consisting of combinations of attributes of an object (e.g. policy). Researcher choice upon the emission reduction policy package is done with some consideration, namely: (1) the burden of premium subsidies (gasoline with higher lead levels) was considered too high by the ministry of finance (Antara News.Com 2008), (2) the UN and some developed countries encourage implementation of programs of $\mathrm{CO} 2$ reduction 'carbon trading' (IPCC 2007), and (3) the issue of traffic congestion has been the subject of widespread discussion in Indonesia (Vivanews.Com 2010).

In the experimental scenarios, participants of this study were assumed to be members of a team drafting "toxic air pollution reduction policy" that will soon be implemented in large cities. The policy is basically a package of programs that are characterized by three attributes the participants must be assessed, namely:

1. Type of vehicle restrictions: (A) setting appropriate number of vehicles in which the even and odd numbers should not be in the street at the same time (daily schedule for even and odd motor vehicle numbers), (B) implementing gasoline price discrimination by raising the price of gasoline for noncommercial vehicles, and (C) establish quotas to restrict number of vehicle sales in Indonesia.
2. Reduction of lead content, by reducing at a level of: $(\mathrm{K}) 15$ percent, (L) 30 percent, (M) 45 percent, and (N) 60 percent of present levels.

3. Economic incentives from the government in the form of policy: (X) the overall elimination of subsidies, (Y) 50 percent removal of subsidies granted now, $(Z)$ to maintain the amount of government subsidies that exist today.

Stimuli were based on alternative choices (government programs) that can be fully exercised by decision makers. Before the experiment was done, all participants were given reading material that explained the importance of reducing air pollution (especially from $\mathrm{CO} 2$ and lead) since medical research shows the increasing illness and mortality resulting from air pollution. The passage also contains an explanation that each policy option certainly has some economic consequences (e.g., production costs or the burden of subsidy if the government chooses to subsidize), social consequences (e.g., political support from the public but also the possibility of social resistance), and environmental degradation (e.g., the fewer the vehicles, the less likely fertile land would be converted to build highways, terminals, and various other facilities). They were also told that until now there is no conclusive study regarding the implications of all these combinations. 
Gadjah MadaInternationalJournal of Business,September-December 2010,Vol.12,No.3

In addition to assessing the strength of each factor's effect, officials' preferences on three combinations of policy elements are also tested. These combinations ("policy packages") are as follows:

(1) Status quo policy. This policy will consist of policy elements that require the least change from existing condition, i.e. $\mathrm{A}+\mathrm{K}+\mathrm{Z}$

(2) "Radical" Change Policy. This policy could be the most "scientific" and the most supported by environmentalists because it requires major departure from cur- rent conditions simply to satisfy the demand of environmental views. It consists of a combination among $\mathrm{C}+\mathrm{X}+\mathrm{N}$.

(3) Popular policy (which consists of $\mathrm{B}+\mathrm{K}+\mathrm{Z}$ ). It is a popular policy because it tries to comply with popular demand: low gasoline price and not much change from the current situation. While from the political stand point this policy might gain support from low to middle income elements of society, it could be a financial burden for the government.

Table 1. Orthogonal Design

\begin{tabular}{|c|c|c|c|c|}
\hline Type & $\mathrm{CO2} / \mathrm{Tin}$ & Subsidy & Status & Cards \\
\hline $\mathrm{A}$ & $\mathrm{L}$ & $\mathrm{Y}$ & Design & 1 \\
\hline $\mathrm{C}$ & M & $\mathrm{X}$ & Design & 2 \\
\hline A & $\mathrm{N}$ & $X$ & Design & 3 \\
\hline $\mathrm{B}$ & $\mathrm{N}$ & Y & Holdout & 4 \\
\hline $\mathrm{C}$ & K & Z & Design & 5 \\
\hline A & M & $\mathrm{Y}$ & Design & 6 \\
\hline B & $\mathrm{N}$ & $X$ & Holdout & 7 \\
\hline $\mathrm{C}$ & $\mathrm{L}$ & $X$ & Design & 8 \\
\hline A & K & $\mathrm{X}$ & Design & 9 \\
\hline $\mathrm{C}$ & K & $\mathrm{X}$ & Holdout & 10 \\
\hline A & M & Z & Design & 11 \\
\hline $\mathrm{A}$ & $\mathrm{L}$ & Z & Design & 12 \\
\hline B & $\mathrm{L}$ & $X$ & Design & 13 \\
\hline B & $\mathrm{K}$ & $\mathrm{Y}$ & Design & 14 \\
\hline B & M & $\mathrm{X}$ & Design & 15 \\
\hline B & $\mathrm{N}$ & Z & Design & 16 \\
\hline A & $\mathrm{L}$ & $\mathrm{X}$ & Holdout & 17 \\
\hline $\mathrm{C}$ & $\mathrm{N}$ & $\mathrm{Y}$ & Design & 18 \\
\hline A & $\mathrm{N}$ & $\mathrm{X}$ & Design & 19 \\
\hline A & $\mathrm{K}$ & $\mathrm{X}$ & Design & 20 \\
\hline
\end{tabular}


Gudono-TheApplication ofChoice-BasedConjointModeltoStudyGovernmentAuthoritiesPreference

\section{Orthogonal Design}

If all combinations of the stimuli are given (i.e., implementing "full factorial design") then there will be thirty six $(=3 \times 4 \times 3)$ combinations of stimuli which should be evaluated by the research participants. By considering the cognitive burden to be borne by the subjects, the full factorial design was clearly not feasible (Maddala et al. 2003). Therefore in this study the researcher used a fractional design (Gudono, upcoming 2011) with stimuli arranged orthogonally. The following is the orthogonal design being used:

\section{Results}

\section{Utility Function}

Table 2 shows the officials' utility estimates of CA outputs. Based on Table 1 the utility function of the toxic gas emission reduction public policy can be developed as follows:

$$
\begin{aligned}
\mathrm{U}= & 0.286(\mathrm{~A})+0.5(\mathrm{~B}) \\
& -0.786(\mathrm{C})+0.143(\mathrm{~K}) \\
& -1.107(\mathrm{~L})+0.107(\mathrm{M}) \\
& +0.857(\mathrm{~N})-0.333(\mathrm{X}) 0286(\mathrm{~A}) \\
& +0.5(\mathrm{~B})-0786(\mathrm{C})+0143(\mathrm{~K}) \\
& -1107(\mathrm{~L})+0107(\mathrm{M})+0857(\mathrm{~N}) \\
& -0333(\mathrm{X})-0.619(\mathrm{Y})+0.952(\mathrm{Z}) \\
& +8.512-0619(\mathrm{Y})+0952(\mathrm{Z}) \\
& +8512 \ldots \ldots \ldots \ldots . .(2)
\end{aligned}
$$

\begin{tabular}{|c|c|c|c|}
\hline & Utility & Estimate & $\begin{array}{l}\text { Std. } \\
\text { Error }\end{array}$ \\
\hline \multirow[t]{3}{*}{ Type } & A & .286 & .937 \\
\hline & B & .500 & 1.098 \\
\hline & $\mathrm{C}$ & -.786 & 1.098 \\
\hline \multirow[t]{4}{*}{ Lead } & K & .143 & 1.217 \\
\hline & $\mathrm{L}$ & -1.107 & 1.217 \\
\hline & M & .107 & 1.217 \\
\hline & $\mathrm{N}$ & .857 & 1.217 \\
\hline \multirow[t]{3}{*}{ Subsidy } & $y \quad x$ & -.333 & .937 \\
\hline & $\mathrm{Y}$ & -.619 & 1.098 \\
\hline & $\mathrm{Z}$ & .952 & 1.098 \\
\hline \multicolumn{2}{|c|}{ (Constant) } & 8.512 & .777 \\
\hline
\end{tabular}

where,

$\mathrm{U}=$ total utility; A, B,.., $\mathrm{Z}$ are the attribute levels being tested.
Table 2. Overall Utility Estimate Overall Utility Estimate

Some utility coefficients in Model 2 are negative values (disutility) which indicates that the level of such features (e.g., C) is less preferred. However, if the attributes are combined as a package with other policy attributes, it is still possible that the value of overall combination would be positive.

\section{Attribute Comparison and Validity Check}

The CA outputs also show a comparison of the importance of each feature as follows.

$$
\begin{array}{ll}
\text { type } & =31.843 \\
\mathrm{CO} 2 / \mathrm{lead} & =47.152 \\
\text { subsidy } & =21.005
\end{array}
$$

The data above show that the policy of reducing lead level has the 
most important weight (47.152\%) than the "type of restriction" $(31.843 \%)$ and "subsidies" (21.005\%). This fact indicates that the public officials prefer to "play safe," because compared to other options, this policy is the most "controllable" and the government could expect least resistance.

From the correlations in Table 3 , it seems that the goodness of fit model is relatively good (Pearson's $\mathrm{R}=0.477$, significant at $\alpha=0.05$ ). Evidence score Kendall's tau also supports this conclu-

Table 3. Correlation

\begin{tabular}{|c|c|c|}
\hline & Value & Sig. \\
\hline Pearson's R & .470 & .033 \\
\hline Kendall's tau $(\tau)$ & .370 & .024 \\
\hline $\begin{array}{l}\text { Kendall's tau }(\tau) \\
\text { for Holdouts }\end{array}$ & .548 & .139 \\
\hline
\end{tabular}

Table 4 (A). Preference Score

\begin{tabular}{|c|c|c|}
\hline $\begin{array}{c}\text { Card } \\
\text { Number }\end{array}$ & ID & Score \\
\hline 1 & 21 & 9.893 \\
\hline 2 & 22 & 7.964 \\
\hline 3 & 23 & 10.107 \\
\hline
\end{tabular}

$\operatorname{sion}(\tau=0.37, \mathrm{p}=0.024$, significant at $\alpha=$ $0.05)$. Cross validation absolute value of Kendall's $\tau$ (tau) of holdouts data is 0.548 , but it is not significant.

\section{Choice Simulator}

One of the advantages of CA is that researchers can compare several policy packages that do not even exist yet. In this case the researcher may conduct simulations of the most valued policy by respondents. In this study the researcher was also interested in evaluating the utility of (a) "status-quo policy", (b) "radical change policy", and (c) popular (according to the appraisal of low to medium income groups), and the results are presented in Table 4 (A) and 4 (B).

Table 4 (A) and (B) list the results of the simulation of the three packages. From the simulation results in Table 4 (A) it is obvious that package II is the most preferred choice (Pref $=7.964$, the smallest among the three alternatives). However, it is still unclear whether at the end this package would ultimately be selected. The data in Table 4 (B) shows the three assessment criteria. Based on the criteria, package I is possibly the policy that is

Table 4 (B). Probability Preference

\begin{tabular}{|c|c|c|c|c|}
\hline Card Number & ID & $\begin{array}{c}\text { Maximum } \\
\text { Utility (a) }\end{array}$ & $\begin{array}{l}\text { Bradley-Terry- } \\
\text { Luce (BTL) }\end{array}$ & Logit \\
\hline 1 & 21 & $64.3 \%$ & $35.1 \%$ & $44.7 \%$ \\
\hline 2 & 22 & $28.6 \%$ & $29.0 \%$ & $31.0 \%$ \\
\hline 3 & 23 & $7.1 \%$ & $35.9 \%$ & $24.3 \%$ \\
\hline
\end{tabular}


Gudono-The Application ofChoice-BasedConjointModeltoStudyGovernmentAuthoritiesPreference

finally selected (according to the method of "maximum utility" and "logit"). If the BTL method is used, the value of package I is only slightly smaller than the value of package III. The simulation results may explain why, based on prior experience, The Indonesian government tends to avoid drastic changes regarding the removal of fuel subsidies and/or is reluctant to implement radical ways of coping with traffic congestion. It is quite reasonable that public dissatisfaction (especially among those of low and medium income groups) is increasing.

\section{Conclusions}

The results of this study indicate that public officials tend to be reluctant to make radical changes related to the issue of $\mathrm{CO} 2$ as well as to reductions in tin/lead emissions into the air, although individually they liked the idea of drastic change. This result indicates that there is cognitive dissonance: government officials individually perceive that they are doing something that is not right or in conflict with their moral views. How this phenomenon would affect their behavior in the long run is not known. Of the three policy attributes, namely "reduction of vehicles on the road," "lead reduction" (through the production of higher quality gasoline), and "subsidies," government officials primarily prefer the second attribute (lead reduction). It seems that participants felt that the policy is most easily controlled and they could expect the least resistance from public. This is also an indication that public officials tend to "play safe" in dealing with environmental issues. As a consequence, Indonesian should not expect that there will be drastic changes in government policy that is associated with the problem of $\mathrm{CO} 2 /$ lead pollution as well as traffic congestion.

The fact that this study uses graduate students as proxies of real government bureaucrats may raise doubts about the extent to which these conclusions really reflect the mindset of Indonesian officials. Cross validation results with holdout data proved to be inconclusive, so it reinforces doubts about the external validity of this research. To obtain a more valid conclusion, the author suggests that in the future researchers should use real working-officials or perhaps members of the House. In addition, the use of ordinary members of the public for replication of this study is also highly recommended to examine the expectation gap between the bureaucrats with the society at large. 
Gadjah MadaInternationalJournal ofBusiness,September-December2010,Vol.12,No.3

\section{References}

Anderson, N. H.. 1991. Contributions to Information Integration Theory. Mahwah, N.J: Erlbaum, USA.

AntaraNews.Com. 2008. Hasil Pembahasan Awal RAPBN 2009 (26 September).

Aronson, E., R. D. Akert, and T. D. Wilson. 2006. Social Psychology (6 $6^{\text {th }}$ ed.). Upper Saddle River, NJ: Pearson Prentice Hall, USA.

Barney, J. B. 2002. Gaining and Sustaining Competitive Advantage. USA: Prentice Hall.

Binder, S., andE. Neumayer. 2005. Environmental pressure group strength and air Pollution: An empirical analysis. Ecological Economics 55 (4). Elsevier: 527-538.

Enicef. 2008. The state of Africa's children 2008. UnicefReport.

Elrod, T., J. J. Louviere, and K. S. Davey. 1992. An empirical comparison of Ratings-based and choice-based conjoint models. Journal of Marketing Research, 29.

FAO. 2010. The State of Food Insecurity in The World. http://www.fao.org/publications /sofi/en/

Gudono (upcoming 2011). Analisis Data Multivariat. Indonesia: BPFE.

Hair, J. F., R. E. Anderson, R. L. Tatham, and W. C. Black. 1995. Multivariate Data Analysis, with Readings. USA: Prentice Hall.

IPCC . 2007. Glossary J-P, in (section): Annex II Glossary. In (book) Pachauri, R. K. and A. Reisinger, Climate Change 2007: Synthesis Report. Contribution of Working Groups I, II and III to the Fourth Assessment Report of the Intergovernmental Panel on Climate Change (Core Writing Team). IPCC, Geneva, Switzerland

Kotri, A. 2006. Analyzing Costumer Value Using Conjoint Anaysis: The Example of Packaging Company. Estonia: Tartu University Press.

Maddala, T., A. P. Kathryn, and J. Reed. 2003. An experiment on simplifying conjoint analysis designs for measuring preferences. Health Economics 12 (12): 1035-1047.

Klein, N.2000. No Logo, Taking Aim at The Brand Bullies. Canada: Knpf.

PME-Indonesia.Com. 2008. Warga Tuntut SBY Tegas Soal Lapindo (November 11).

RakyatMerdekaOnline. 2010. Gubernur DKIJakarta Saat Ini Lebih Buruk Dari Gubernur Sebelumnya (January 11).

Rosko M. D., H. DeVita, W. F. McKenna, and L. R. Walker. 1985. Strategic marketing applications of conjoint analysis: An HMO perspetive. Journal of Health Case Marketing 5:27-38.

Rubinstein, A. 1998. Modeling bounded rationality. USA: MIT Press.

Schaupp, L. C. and F. Bélanger. 2005. Conjoint analysis of online consumer satisfaction. Journal of Electronic Commerce Research 6(2): 95-111.

United Nations Division for sustainable Development. 2007. Documents: Sustainable Development Issues. http://www.un.org/esa/sustdev/documents/ocs_sdissues.htm.

UN-Habitat . 2007. Annual Report. United Nations 
Gudono-TheApplication ofChoice-BasedConjointModeltoStudyGovernmentAuthoritiesPreference

United Nations Framework Convention on Climate Change. 2010. Legal Considerations Relating to A Possible Gap between the First and Subsequent Commitment Periods. FCCC/KP/AWG.

Vivanews.Com. 2010. Jumlah Kendaraan di Jakarta 9, 6 Juta (January 12).

Wachernagel, M. and W. E. Rees. 1995. Our Ecological Footprint: Reducing Human Impact On Earth. Canada: New Society Publisher.

WaspadaOnline. 2010. Amin Rais: SBY Selalu Lamban (April 8).

World Bank. 2006. Third Water Supply and Sanitation for Low Income Communities Project(June 2006).

World Bank. 2008. World Bank Development Indicator(September). 
